\title{
What Factors Influence Language Impairment? Considering Resilience as well as Risk
}

\author{
Gina Conti-Ramsden ${ }^{a}$ Kevin Durkin ${ }^{b}$ \\ ${ }^{a}$ The University of Manchester, Manchester, and ${ }^{b}$ School of Psychological Sciences and Health, \\ University of Strathclyde, Glasgow, UK
}

\section{Key Words}

Language impairment $\cdot$ Resilience $\cdot$ Risk factors

\begin{abstract}
The considerable variation observed in the profiles of children with language impairment (LI) raises challenges for the diagnosis, treatment and prevention of language difficulties, in particular since LI can present substantial issues calling for the investment of clinical, educational and public health resources. In this review paper, we examine biological, psychological and environmental factors that appear to influence the developmental course of LI. In this review paper we are interested not only in examining deficits and risk factors but also in identifying strengths of children with LI that can act as protective factors providing the child with a scaffold for more positive development and better outcomes.
\end{abstract}

$$
\begin{aligned}
& \text { C } 2016 \text { The Author(s) } \\
& \text { Published by S. Karger AG, Basel }
\end{aligned}
$$

\section{What Factors Influence Language Impairment? Considering Resilience as well as Risk}

Children with language impairment (LI) have deficits in the ability to learn and use language (expressive and/ or receptive) despite otherwise normal development.
Approximately $7 \%$ of children are affected by LI [1]. This means that, on current UK birth rates, every year over 56,000 children start school with language difficulties.

Although LI has been conceptualized as a relatively 'pure' disorder of language, the condition is quite heterogeneous [2]. Research indicates developmental interactions between LI and difficulties acquiring literacy skills and more general non-verbal abilities throughout middle childhood, adolescence and beyond [3-5]. Children with language difficulties are at risk of less successful developmental and educational outcomes [6-9]. These children are more vulnerable to academic failure, social exclusion, behavioural and emotional difficulties, and to being bullied $[5,10,11]$. Yet negative sequelae are not inevitable. Some individuals achieve positive outcomes in a number of areas of functioning.

The considerable variation observed in LI raises challenges for the diagnosis, treatment and prevention of language difficulties, in particular since LI can present substantial issues calling for the investment of clinical, educational and public health resources. To date, much of the scientific effort focussed on LI has been on deficits and analysis of risk factors. In this paper, we also focus on resilience. We are interested in identifying strengths of children with LI that can act as protective factors providing the child with a scaffold for more positive development

\begin{tabular}{lll}
\hline KARGER 125/s & $\begin{array}{l}\text { @ 2016 The Author(s) } \\
\text { Published by S. Karger AG, Basel }\end{array}$ \\
& $\begin{array}{l}\text { Karger } \\
\text { Open caccess }\end{array}$ \\
E-Mail karger@karger.com & $\begin{array}{l}\text { This article is licensed under the Creative Commons Attribution 4.0 } \\
\text { www.karger.com/fpl }\end{array}$ & $\begin{array}{l}\text { International License (CC BY) (httr://www.karger.com/Services/ } \\
\text { OpenAcessLicense). Usage, derivative works and distribution are } \\
\text { permitted provided that proper credit is given to the author and the } \\
\text { original publisher. }\end{array}$
\end{tabular}

Prof. Gina Conti-Ramsden

The University of Manchester

Human Communication and Deafness Ellen Wilkinson Building

Oxford Road, Manchester M13 9PL (UK)

E-Mail gina.conti-ramsden@ manchester.ac.uk 
and better outcomes. In this paper we examine biological, psychological and environmental factors that appear to influence the developmental course of LI.

\section{Terminological Debate}

Although LI is recognized internationally [12], professionals and academics working in speech and language therapy, psychology and education have struggled to find a common language to refer to these children. Currently, we do not have an agreed label that fosters information exchange and collaboration across disciplines and across different stages of children's development. Labels include 'specific language impairment', 'language disorders', 'speech, language and communication needs', 'developmental language delay' and 'primary language difficulties', and the list could go on. In addition, across the English-speaking world, there is variation both within and between countries as to how LI should be diagnosed [13, 14]. The good news is that a multinational, multidisciplinary effort is currently underway to develop a diagnostic and terminological consensus within the field of LI [15]. In this article, we use the term 'language impairment'.

\section{Children with LI}

Typically, LI comes to the attention of clinicians as a result of concern from significant others about the child's progress with language learning. Children who develop LI are usually characterized by having language difficulties from the outset of the language-learning process. Instead of reaching developmental language milestones on schedule (first words around a child's first birthday, word combinations around the child's second birthday), most children with LI are slow from the beginning. It is a hallmark of LI that the majority of these children are late talkers: they are late in acquiring their first words and in putting together their first word combinations. It is not the case that children with LI start developing language normally and then stop and become delayed or lose what they have learned. Occurrence of 'language loss' in infancy is reported in some children with autism spectrum disorders but not in children with specific LI. This appears to be a distinguishing feature between the two disorders [16] and hence can be particularly useful for the differential diagnosis between specific LI and autism spectrum disorders in the preschool period. In the pre- school and early childhood period, difficulties with the sound system of the language, i.e., phonology, can cooccur with LI but are not considered to be a hallmark of the disorder. By middle childhood, problems with sound production are usually resolved or less evident (unless there is orofacial motor difficulty/apraxia) and most children with LI are intelligible. It is also worth noting that a minority (5\%) of children with LI are not late talkers [17]. These children can develop problems late, after having acquired single words. For these children, word combinations pose the biggest challenge in the trajectory of their language difficulties.

\section{What Factors Influence LI?}

It has become clear that $\mathrm{LI}$ is not the result of a single risk factor. A number of theories have been put forward, each focusing on a particular feature or set of characteristics, all of which have received some empirical support. It seems likely that multiple risk factors are implicated, and we argue that these can interact with protective factors to exacerbate or ameliorate LI. In prevention and intervention of LI it is important to examine strengths as well as difficulties (fig. 1).

\section{Biological Risk: Gender and}

Genetic and Neurobiological Factors

LI is more common in boys than in girls. The ratio of males to females is approximately $2: 1$ [for a review see 18] and can be higher in samples from specialized settings such as language units [3:1; see 19] and language schools [5:1; see 20]. However, large epidemiological studies such as that by Tomblin et al. [1] have found approximately equal proportions of males and females with LI. Why may this be the case? What prompts parents/teachers to refer boys to services (and under-refer girls)? There is evidence that boys with LI are more likely than girls to have associated behavioural problems, 'acting out' their frustrations [for a review see 21]. There is also some evidence to suggest that boys with language comprehension problems are more likely to exhibit aggression and externalizing problems [22, 23]. Looking behind behaviour is crucial (see the RALLI video clip; https://www.youtube.com/ watch? $\mathrm{v}=\mathrm{WTySmn} \_\mathrm{X} 80$ ), as is a detailed assessment of language comprehension [24] with appropriate targeted interventions (see, e.g., Contextualized Language Intervention strategies $[25,26])$.

There is strong evidence - from family aggregation studies, twin studies, adoption studies, pedigree analyses 


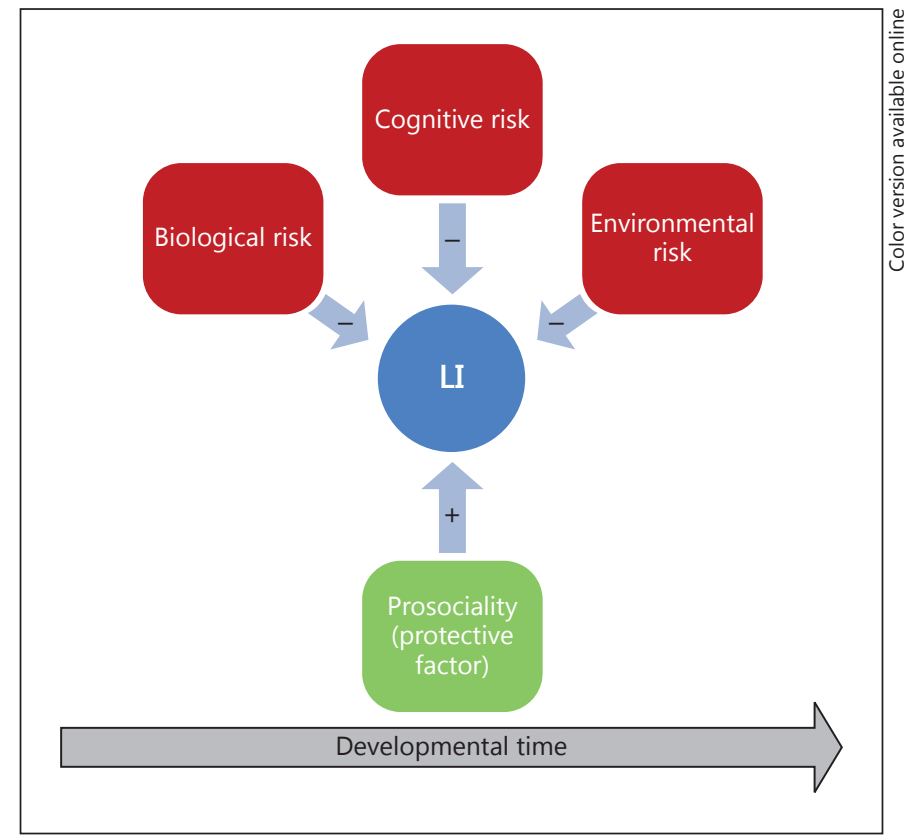

Fig. 1. Risk and protective factors in LI.

and genetic linkage analyses - that LI runs in families. The majority of children with LI have a family history of language difficulties, with a first-degree relative usually affected. The contribution of genetic factors is most clearly indicated in twin studies, such that identical twins have a higher concordance for LI than non-identical twins [27]. Patterns of inheritance appear to be complex, involving interactions between multiple genes [28]. We do know, however, that siblings of affected children are at a higher risk. On average, $30 \%$ of siblings develop LI [29]. These data on sibling genetic liability provide crucial information with regard to prevention. However, in reality limited resources are a barrier to action. How many services do we know that provide vigilant developmental assessments of siblings of children with LI?

Technological advances have made it possible to examine brain development in children with LI. However, few atypicalities have been identified. The most consistent neuroimaging findings suggest leftward asymmetry and an atypical cerebral volume. Electrophysiological evidence suggests abnormal auditory processing [30, 31]. However, these abnormalities have also been observed in other developmental disorders. Thus, further research is needed to identify distinctive features of brain development in individuals with LI. As yet we do not have neurobiological markers for LI.

Factors Influencing LI

\section{Cognitive Risks: Memory Limitations}

Different approaches emphasize risk factors in relation to deficits in different systems. Memory, information processing and temporal auditory processing mechanisms involved in the representation of grammar have all been proposed as influential risk factors for LI. In this article we focus on memory risk factors, in particular phonological short-term memory and procedural memory impairments in LI.

Research into the short-term memory capacity of children with LI has used Baddeley's model of working memory $[32,33]$. This model conceptualizes phonological short-term memory (PSTM) as a domain-specific area for the temporary storage of verbal information.

Gathercole and Baddeley [34, 35] were among the first to demonstrate that non-word repetition, a measure of phonological short-term memory, was a fairly reliable risk factor for LI, as it discriminated between children with LI and either age- or language-matched, typically developing peers. Non-word repetition abilities have also been found to be heritable, as evidenced by twin and family studies involving children with LI $[28,36]$.

Measures of PSTM, particularly as indexed by nonword repetition abilities, have since been widely used in research on children with LI. The majority of studies have involved school-age children [37-40], and available tools for measuring PSTM have also focused on children over 4 years of age [41]. However, Chiat and Roy [42, 43] studied non-word and word repetition abilities in children as young as 2 years of age. They found that early difficulties with phonological processing and memory, as indexed by non-word and word repetition at 2-3 years of age, were not only correlated with concurrent language difficulties but were also predictive of language problems 2 years later (at 4-5 years of age). These authors have developed a clinical instrument, the Early Repetition Battery (ERB) [44], that provides a tool for the assessment of PSTM abilities in children as young as 2 years of age. Despite the availability of the ERB and other such instruments, PSTM is not yet routinely part of clinical assessment. The evidence indicates that it is time to include PSTM in the assessment of LI.

It is also worth noting that processing-dependent tasks such as non-word repetition have more validity across different languages [45-48]. In the assessment of multilingual children and children with differing backgrounds for example, children of migrant families who do not speak, or are less proficient in, the majority language - the assessment of memory processes provides a promising tool for differentiating risk of LI from linguistic differences attributable to experiential factors. 
In terms of long-term memory, it has been proposed that the grammatical impairments in children with LI are primarily caused by deficits in the procedural memory system [49]. The procedural memory system underlies the implicit learning, storage and retrieval of skills and knowledge [50,51]. Learning via the procedural memory system is often slow, with repetition or repeated exposures to the information required in order for a skill or knowledge to be learned [52], for example, learning grammatical morphemes such as past tense '-ed' in English. Once information has been acquired, though, new knowledge and skills may be used without awareness. The learning and retrieval of information from the procedural memory system is said to be implicit. There is evidence that procedural memory deficits are a risk factor for LI.

A number of studies have found procedural learning is impaired in children with LI, even when the stimuli are non-verbal in nature [53-55]. To our knowledge, however, the assessment of procedural learning in children with LI is limited to research contexts, given the complexities of evaluating implicit processes. Further translational research is needed to develop tools which are usable in clinical contexts.

\section{Environmental Risk: Parental Education and}

\section{Socioeconomic Status}

Children are part of families and families are complex systems [56]. Children grow up in homes and social environments which can vary considerably in terms of parental practices and beliefs (associated with parental education) as well as access to experiences and the material worlds such as toys to play with or books to read (socioeconomic status). In general, samples of children with LI contain disproportionately high numbers of individuals from socioeconomically disadvantaged backgrounds [57, 58]. Children living in poverty show language delays of 2 or more years by school entry [59].

One conceptualization of disadvantage has focused on children's linguistic input. Children of 'professional' parents who are more educated hear approximately 3 times more oral language than children of parents with lower education levels [60, 61]. It is important to note, however, that there is little convincing evidence to support the claim that inadequate linguistic input (amount of parental talk, or use of child-directed speech) contributes to LI $[18,62]$. We know from cross-cultural research that language development is robust to variation in the amount and type of linguistic input needed for learning a native language. In Samoa and Papua New Guinea, for example, adults speak to children as they speak to adults - and much less frequently than parents of children in Western cultures - and children acquire language at the same pace as elsewhere in the world [63].

The regular linguistic environment of children with LI is simply not sufficient to overcome their language difficulties [64]. Children with LI require specialist input (from speech and language therapists or teachers). They need rich, scaffolded linguistic environments where specific aspects of language are targeted, highlighted, clarified and practiced to match the child's needs [65]. This evidence implies the need for appropriate language assessment of preschool children from families of low socioeconomic status, increased availability of speech and language therapy services throughout the school years as well as speech and language therapy input and teachertherapist joint working in the classroom [59].

\section{Protective Factors: Sociability and Prosociality}

Children with LI are sociable. Unlike children with autism spectrum disorders, those with LI want to interact socially [66]. In addition, they bring positive 'prosocial' attributes to interactions. Prosociality involves behaviours that are responsive to others' needs and welfare, such as being helpful and sharing, showing kindness and consideration, cooperating with others and expressing empathy [67]. Research on LI and prosociality is only just emerging. Our own longitudinal work indicates that children with LI are moderately to highly prosocial and that prosociality confers developmental protection for these children [68].

Prosociality contributes to positive peer and social relationships in LI as well as emotional adjustment $[9,69]$. For example, participation in prosocial peer relationships appears to provide support for children who have negative experiences (such as bullying), facilitating coping and psychosocial resilience [70]. Prosocial adolescents are also reported to be less likely to engage in antisocial behaviours [71].

How often do we assess the level of prosociality in children with LI? How often do we monitor its developmental progress? What do we do to build on it? We believe it is crucial to identify and, if appropriate, further develop strengths of children with LI. The Strengths and Difficulties Questionnaire (SDQ) [72] is a freely available questionnaire that can be used by therapists, teachers, parents and also children and young people themselves. The SDQ has been used extensively in psychological research and has norms for children 3-16 years of age. The dedicated website provides downloadable materials and information (http://www.sdqinfo.com/). 
To our knowledge there has not been a systematic effort to build on the prosocial tendencies of children with LI in intervention programmes. It is more common to target areas of deficits rather than strengths. A contrasting example is intervention efforts with children with autism spectrum disorders. There is an abundance of programmes that target improving the social skills and prosocial behaviours of children with autism spectrum disorders, although the effectiveness of such interventions has been limited [73]. It may well be time to re-think intervention goals for children with LI that include developing existing strengths that can in turn influence longerterm outcomes [see also 7].

\section{Concluding Remarks}

Risk and protective factors are crucial in the prevention and identification of LI. In addition to providing evidence-based information to parents who are concerned about their child, early identification of risk and protective factors affords the opportunity for targeted interventions. Language intervention has the potential to change the developmental course of children's language difficulties and improve long-term outcomes. Evidence suggests that there is fluidity in the rate of language growth in the preschool and early school years; some young children with LI experience accelerated growth during this early period of development [74]. The available literature also suggests that language continues to develop in this population with intervention. Older children and young people with LI continue to learn language at a steady pace beyond the early school years [3]. The above considerations - coupled with evidence of the efficacy of speech and language therapy treatment, particularly for interventions of longer duration $[75,76]-$ make a strong argument for a risk-resilience developmental approach to prevention, identification and intervention in children with LI.

\section{Acknowledgements}

We acknowledge the support of the Economic and Social Research Council (grant RES-062-23-2745), the Nuffield Foundation (EDU 8366, EDU 32083) and the Wellcome Trust (060774).

\section{Disclosure Statement}

We declare no conflict of interests.

\section{References}

1 Tomblin JB, Records NL, Buckwalter P, Zhang X, Smith E, O'Brien M: Prevalence of specific language impairment in kindergarten children. J Speech Lang Hear Res 1997;40: $1245-1260$

2 Conti-Ramsden G, Durkin K: Language impairment and adolescent outcomes; in Durkin K, Schaffer HR (eds): The Wiley Handbook of Developmental Psychology in Practice: Implementation and Impact. Chichester, Wiley, 2016, pp 407-439.

3 Conti-Ramsden G, St Clair MC, Pickles A, Durkin K: Developmental trajectories of verbal and nonverbal skills in individuals with a history of specific language impairment: from childhood to adolescence. J Speech Lang Hear Res 2012;55:1716-1735.

4 Conti-Ramsden G, Durkin K: Phonological short-term memory, language and literacy: developmental relationships in early adolescence in young people with SLI. J Child Psychol Psychiatry 2007;48:147-156.

5 St Clair MC, Pickles A, Durkin K, ContiRamsden G: A longitudinal study of behavioural, emotional and social difficulties in in- dividuals with a history of specific language impairment (SLI). J Commun Disord 2011; 44:186-199.

6 Cohen NJ, Farnia F, Im-Bolter N: Higher order language competence and adolescent mental health. J Child Psychol Psychiatry 2013;54:733-744

7 Durkin K, Mok PL, Conti-Ramsden G: Core subjects at the end of primary school: identifying and explaining relative strengths of children with specific language impairment (SLI). Int J Lang Commun Disord 2015;50:226-240.

8 Durkin K, Conti-Ramsden G: Language, social behavior, and the quality of friendships in adolescents with and without a history of specific language impairment. Child Dev 2007; 78:1441-1457.

9 Mok PL, Pickles A, Durkin K, Conti-Ramsden G: Longitudinal trajectories of peer relations in children with specific language impairment. J Child Psychol Psychiatry 2014;55: 516-527.

10 Conti-Ramsden G, Durkin K, Simkin Z, Knox E: Specific language impairment and school outcomes. I. Identifying and explaining vari- ability at the end of compulsory education. Int J Lang Commun Disord 2009;44:15-35.

11 Durkin K, Conti-Ramsden G: Young people with specific language impairment: a review of social and emotional functioning in adolescence. Child Lang Teach Ther 2010;26:105121.

12 American Psychiatric Association: Diagnostic and Statistical Manual of Mental Disorders, ed 5. Arlington, American Psychiatric Association, 2013.

13 Bishop DVM: Ten questions about terminology for children with unexplained language problems. Int J Lang Commun Disord 2014; 49:381-415.

14 Reilly S, Tomblin B, Law J, McKean C, Mensah FK, Morgan A, Wake M: Specific language impairment: a convenient label for whom? Int J Lang Commun Disord 2014;49: 416-451.

15 Bishop DVM, Snowling MJ, Thompson PA, Greenhalgh T; CATALISE Consortium: Identifying language impairment in children: a multinational and multidisciplinary Delphi consensus study. Manuscript under review. 
16 Pickles A, Simonoff E, Conti-Ramsden G, Falcaro M, Simkin Z, Charman T, Baird G: Loss of language in early development of autism and specific language impairment. J Child Psychol Psychiatry 2009;50:843-852.

17 Ukoumunne OC, Wake M, Carlin J, Bavin EL, Lum J, Skeat J, Reilly S: Profiles of language development in pre-school children: a longitudinal latent class analysis of data from the Early Language in Victoria Study. Child Care Health Dev 2012;38:341-349.

18 Leonard LB: Children with Specific Language Impairment. Cambridge, MIT Press, 2014.

19 Conti-Ramsden G, Botting N: Characteristics of children attending language units in England: a national study of 7-year-olds. Int J Lang Commun Disord 1999;34:359-366.

20 Haynes C: A longitudinal study of languageimpaired children from a residential school; in Fletcher P, Hall D (eds): Specific Speech and Language Disorders in Children. London, Whurr, 1992, pp 166-182.

21 Yew SGK, O'Kearney R: Emotional and behavioural outcomes later in childhood and adolescence for children with specific language impairments: meta-analyses of controlled prospective studies. J Child Psychol Psychiatry 2013;54:516-524.

22 Beitchman J, Brownlie EB: Language Disorders in Children. Oxford, Hogrefe, 2013, vol 28.

23 Brownlie EB, Beitchman JH, Escobar M, Young A, Atkinson L, Johnson C, Douglas L: Early language impairment and young adult delinquent and aggressive behavior. J Abnorm Child Psychol 2004;32:453-467.

24 Conti-Ramsden G, Durkin K: Language development and assessment in the preschool period. Neuropsychol Rev 2012;22:384-401.

25 Gillam SL, Gillam RB, Reece K: Language outcomes of contextualized and decontextualized language intervention: results of an early efficacy study. Lang Speech Hear Serv Sch 2012;43:276-291.

26 Kamhi AG: Improving clinical practices for children with language and learning disorders. Lang Speech Hear Serv Sch 2014;45:92103.

27 Bishop DVM: The role of genes in the etiology of specific language impairment. J Commun Disord 2002;35:311-328.

28 Bishop DVM: Developmental cognitive genetics: how psychology can inform genetics and vice versa. Q J Exp Psychol (Hove) 2006; 59:1153-1168.

29 Choudhury N, Benasich AA: A family aggregation study: the influence of family history and other risk factors on language development. J Speech Lang Hear Res 2003;46:261272.

30 Shevell MI: Present conceptualization of early childhood neurodevelopmental disabilities. J Child Neurol 2010;25:120-126.

31 Webster RI, Shevell MI: Neurobiology of specific language impairment. J Child Neurol 2004;19:471-481.
32 Baddeley AD: Working Memory. Oxford, Oxford University Press, 1986.

33 Baddeley A: Working memory and language: an overview. J Commun Disord 2003;36:189208.

34 Gathercole SE, Baddeley AD: Evaluation of the role of STM in the development of vocabulary in children: a longitudinal study. J Mem Lang 1989;28:200-213.

35 Gathercole SE, Baddeley AD: Phonological memory deficits in language-disordered children: is there a causal connection? J Mem Lang 1990;29:336-360.

36 Bishop DVM, North T, Donlan C: Nonword repetition as a behavioural marker for inherited language impairment: evidence from a twin study. J Child Psychol Psychiatry 1996; 37:391-403.

37 Archibald LMD, Gathercole SE: Nonword repetition: a comparison of tests. J Speech Lang Hear Res 2006;49:970-983.

38 Botting N, Conti-Ramsden G: Non-word repetition and language development in children with specific language impairment (SLI). Int J Lang Commun Disord 2001;36:421-432.

39 Conti-Ramsden G, Botting N, Faragher B: Psycholinguistic markers for specific language impairment (SLI). J Child Psychol Psychiatry 2001;42:741-748.

40 Criddle MJ, Durkin K: Phonological representation of novel morphemes in children with SLI and typically developing children. Appl Psycholinguist 2001;22:363-382.

41 Gathercole SE, Baddeley AD: The Children's Test of Nonword Repetition. London, Psychological Corporation, 1996

42 Chiat S, Roy P: The Preschool Repetition Test: an evaluation of performance in typically developing and clinically referred children. J Speech Lang Hear Res 2007;50:429-776.

43 Chiat S, Roy P: Early phonological and sociocognitive skills as predictors of later language and social communication outcomes. J Child Psychol Psychiatry 2008;49:635-645.

44 Seeff-Gabriel B, Chiat S, Roy P: Early Repetition Battery. London, Pearson Assessment, 2008.

45 Campbell T, Dollaghan C, Needleman H, Janosky J: Reducing bias in language assessment: processing-dependent measures. J Speech Lang Hear Res 1997;40:519-525.

46 Conti-Ramsden G: Processing and linguistic markers in young children with specific language impairment (SLI). J Speech Lang Hear Res 2003;46:1029-1037.

47 Lukács Á, Kas B, Leonard LB: Case marking in Hungarian children with specific language impairment. First Lang 2013;33:331-353.

48 Sundström S, Samuelsson C, Lyxell B: Repetition of words and non-words in typically developing children: the role of prosody. First Lang 2014;34:428-449.

49 Ullman MT, Pierpont EI: Specific language impairment is not specific to language: the procedural deficit hypothesis. Cortex 2005; 41:399-433.
50 Gabrieli JDE: Cognitive neuroscience of human memory. Annu Rev Psychol 1998;49: 87-115.

51 Squire LR, Zola SM: Structure and function of declarative and nondeclarative memory systems. Proc Natl Acad Sci USA 1996;93: 13515-13522.

52 Packard MG, Knowlton BJ: Learning and memory functions of the basal ganglia. Annu Rev Neurosci 2002;25:563-593.

53 Evans JL, Saffran JR, Robe-Torres K: Statistical learning in children with specific language impairment. J Speech Lang Hear Res 2009;52: 321-335.

54 Lum JA, Conti-Ramsden G, Page D, Ullman MT: Working, declarative and procedural memory in specific language impairment. Cortex 2012;48:1138-1154.

55 Lum JA, Conti-Ramsden G, Morgan AT, Ullman MT: Procedural learning deficits in specific language impairment (SLI): a meta-analysis of serial reaction time task performance. Cortex 2014;51:1-10.

56 Cummings EM, Schatz JN: Family conflict, emotional security, and child development: translating research findings into a prevention program for community families. Clin Child Fam Psychol Rev 2012;15:14-27.

57 Roy P, Chiat S: Language and socioeconomic disadvantage: teasing apart delay and deprivation from disorder; in Marshall C (ed): Current Issues in Developmental Disorders. Hove, Psychology Press, 2013, pp 125-150.

58 Toppelberg CO, Shapiro T: Language disorders: a 10-year research update review. J Am Acad Child Adolesc Psychiatry 2000;39:143152.

59 Nelson KE, Welsh JA, Trup EMV, Greenberg MT: Language delays of impoverished preschool children in relation to early academic and emotion recognition skills. First Lang 2010;31:164-194.

60 Evans GW: The environment of childhood poverty. Am Psychol 2004;59:77-92.

61 Hart B, Risley TR: Meaningful Differences in the Everyday Experience of Young American Children. Baltimore, PH Brookes, 1995.

62 Lieven EV: Interactional style and children's language learning. Top Lang Disord 1984;4: 15-23.

63 Mead M, Boas F: Coming of Age in Samoa. Harmondsworth, Penguin, 1973.

64 Bishop DVM, Leonard LB: Speech and Language Impairments in Children: Causes, Characteristics, Intervention and Outcome. Hove, Psychology Press, 2000.

65 Law J, Garrett Z, Nye C: Speech and language therapy interventions for children with primary speech and language delay or disorder. Cochrane Database Syst Rev 2003;3: CD004110.

66 Wadman R, Durkin K, Conti-Ramsden G: Self-esteem, shyness, and sociability in adolescents with specific language impairment (SLI). J Speech Lang Hear Res 2008;51:938952 
67 Jensen K, Vaish A, Schmidt MF: The emergence of human prosociality: aligning with others through feelings, concerns, and norms. Front Psychol 2014;5:822.

68 Toseeb U, Pickles A, Durkin K, Botting N, Conti-Ramsden G: Prosociality from early adolescence to young adulthood: a longitudinal study of individuals with a history of language impairment. Manuscript under review.

69 Conti-Ramsden G, Mok P, Durkin K, Pickles A, Toseeb U, Botting N, Conti-Ramsden G: Predictors of divergent developmental trajectories of emotional symptoms in children with language impairment. Manuscript under review.
70 Griese ER, Buhs ES: Prosocial behavior as a protective factor for children's peer victimization. J Youth Adolesc 2014;43:1052-1065.

71 Carlo G, Vicenta Mestre M, McGinley MM, Tur-Porcar A, Samper P, Opal D: The protective role of prosocial behaviors on antisocial behaviors: the mediating effects of deviant peer affiliation. J Adolesc 2014;37:359-366.

72 Goodman R: The Strengths and Difficulties Questionnaire: a research note. J Child Psychol Psychiatry 1997;38:581-586.

73 Bellini S, Peters JK, Benner L, Hopf A: A metaanalysis of school-based social skills interventions for children with autism spectrum disorders. Remedial Spec Educ 2007;28:153162.
74 Bishop DVM, Edmundson A: Language-impaired 4-year-olds: distinguishing transient from persistent impairment. J Speech Hear Disord 1987;52:156-173.

75 Law J, Garrett Z, Nye C: The efficacy of treatment for children with developmental speech and language delay/disorder. J Speech Lang Hear Res 2004;47:924-943.

76 Zeng B, Law J, Lindsay G: Characterizing optimal intervention intensity: the relationship between dosage and effect size in interventions for children with developmental speech and language difficulties. Int J Speech Lang Pathol 2012;14:471-477. 